Www.jmscr.igmpublication.org

Impact Factor (SJIF): 6.379

Index Copernicus Value: 79.54

ISSN (e)-2347-176x ISSN (p) 2455-0450

crossrefDOI: https://dx.doi.org/10.18535/jmscr/v6i10.163

Journal Of Medical Science And Clinical Research

IGM Publication

An Official Publication of IGM Publication

\title{
Role of Diagnostic Laparoscopy in non Specific Abdominal Pain
}

\author{
Authors \\ Dr P.Vinoth ${ }^{1 *}$, Dr R. Ramesh ${ }^{2}$ \\ ${ }^{1}$ Post Graduate, Department of General Surgery, Rajah Muthiah Medical College and Hospital, \\ Chidambaram, Cuddalore, Tamil Nadu, India \\ ${ }^{2}$ Professor and Head of Unit, Department of General Surgery, Rajah Muthiah Medical College and Hospital, \\ Chidambaram, Cuddalore, Tamil Nadu, India
}

\begin{abstract}
Background: Diagnostic Laparoscopy provides us with good view of whole peritoneal cavity there by clinching diagnosis. In General population Appendicular pathology is the leading etiology of non specific abdominal pain, it is about 33\%, followed by adhesion 23\%,positive outcome in 1 month follow up period is $80 \%$,in 3 months follow up period $90 \%$ patients got complete relief.

Patients and Methods: Clinical material for this study was obtained from 50 patients with abdominal pain for three months or more where other clinical symptoms and investigations are not conclusive, attending the Out Patient Department and admitted to Rajah Muthiah Medical College and Hospital, willing for diagnostic laparoscopy. The overall efficacy and outcome of this work includes finding the etiology of Non specific abdominal pain, thereby making a definite diagnosis and to assess the response to treatment in relieving pain after three months.

Results: Appendicular pathology is the leading etiology of Non specific abdominal pain. Diagnostic laparoscopy help us to initiate appropriate treatment in this difficult patient group and positive outcome of pain relief (relief/reduction of pain after diagnostic laparoscopy) was observed in $90 \%$ of patients.

Conclusion: Diagnostic laparoscopy is a safe, relatively cost-effective and efficient method for finding out the etiology of chronic abdominal pain and to provide specific interventions.

Keywords: Chronic abdominal pain, Adhesions, Biopsy, Hernia, Diagnostic laparoscopy, Pain relief.
\end{abstract}

\section{Introduction}

In general, Chronic abdominal pain is the common clinical scenario which poses a diagnostic difficulty to both physician and surgeon. Almost $40 \%$ of patients, Despite of undergoing large number of investigations, diagnosis remains obscure. ${ }^{1-4}$ Chronic abdominal pain affects the physical well being of the patients and leading to significant mental depression., ${ }^{5,6}$ The leading structural causes include intestinal adhesions ${ }^{7,8}$ in cases with past h/o abdominal surgeries, ${ }^{9}$ appendicular causes, mesenteric lymphadenopathy (apart from tuberculosis, it also occurs in gastroenteritis, enteric fever or infective colitis), biliary causes, abdominal tuberculosis and hernia; while functional causes include functional dyspepsia, various motility dysfunction and irritable bowel disease. Abdominal wall pain is often misdiagnosed commonly as visceral pain. ${ }^{10,11}$ Despite investigations such as computed tomography scan, ultrasonography, etc., it is difficult to reach to an accurate diagnosis and 
represent a major diagnostic challenge to the surgeon. ${ }^{12}$ A new tool has been added to our knowledge, with the introduction of laparoscopic surgery. ${ }^{13,14}$ Laparoscopy can identify abnormal findings and improve the outcome in a majority of patients with abdominal pain for three months or more, as it allows surgeons to see and treat many abdominal conditions that cannot be diagnosed otherwise. $^{4,15}$ Laparoscopic surgery has changed the view of many diseases.20Diagnostic laparoscopy now become the preferred procedure for non specific abdominal pain.

\section{Aim}

To evaluate the diagnostic and therapeutic value of Diagnostic laparoscopy in non specific abdominal pain. Patients with non specific abdominal pain where other clinical symptoms and investigations are not conclusive, intra operative findings, various occult etiology and clinical improvement are evaluated.

\section{Objectives}

- To identify the various etiologies of abdominal pain for three months or more.

- To study the efficacy of diagnostic laparoscopy in management of abdominal pain for three months or more.

- The accuracy of diagnostic laparoscopy in patients with abdominal pain for three months or more are analysed.

\section{Patients and Methods}

This is a descriptive cross-sectional study, which included 50 consecutive patients admitted in surgical unit from February 2017 to October 2018, who presented with a h/o abdominal pain for three months or more. After thorough history taking and clinical examination, patients were subjected to routine basic investigations and relevant imaging studies.All these details were entered in the clinical proforma. For patients in whom imaging studies were inconclusive about the etiology of chronic abdominal pain were subjected to diagnostic laparoscopy and the necessary surgical methods were employed as per the etiology after getting informed valid written consent.

Patients were followed up at regular intervals post-discharge and then 3 months after the procedure for subjective assessment of pain was done. The findings and outcomes of laparoscopy were recorded and analyzed.

\section{Results}

\section{Baseline characteristics of studied patients Age Distribution}

\begin{tabular}{|l|c|}
\hline AGE & PATIENT \\
\hline $15-25$ & 18 \\
\hline $26-35$ & 12 \\
\hline $36-45$ & 8 \\
\hline $46-55$ & 12 \\
\hline Total & 50 \\
\hline
\end{tabular}

\section{Mean age $=34$ years}

Most of them in the age group between 15-25 in adult population

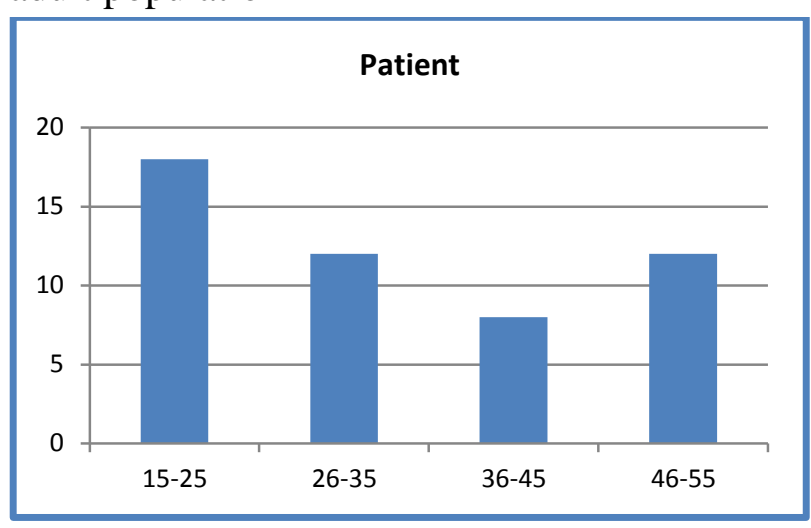

\section{Sex Distribution}

\begin{tabular}{|l|c|}
\hline Gender & Patient \\
\hline Male & 23 \\
\hline Female & 27 \\
\hline Total & 50 \\
\hline
\end{tabular}

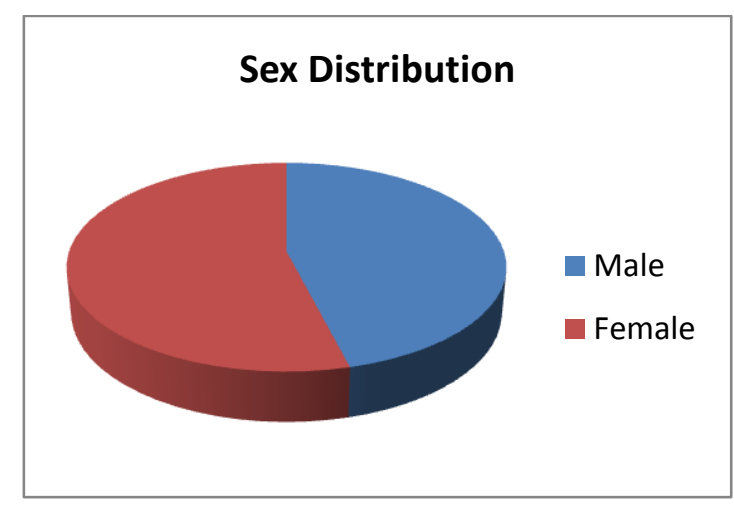


- Almost male Vs female ratio is equal in study population..

- Slightly higher in females

\section{Duration of Pain}

Mean $=6$ month (3-24 months)
Most of them had pain duration around 6 months, not more than 2 years.

\section{Site of Pain}

\begin{tabular}{|l|c|}
\hline Right Upper Quadrant & $5(10 \%)$ \\
\hline Right Lower Quadrant & $30(60 \%)$ \\
\hline Left Upper Quadrant & $2(3 \%)$ \\
\hline Left Lower Quadrant & $8(17 \%)$ \\
\hline Periumbilical & $10(20 \%)$ \\
\hline
\end{tabular}

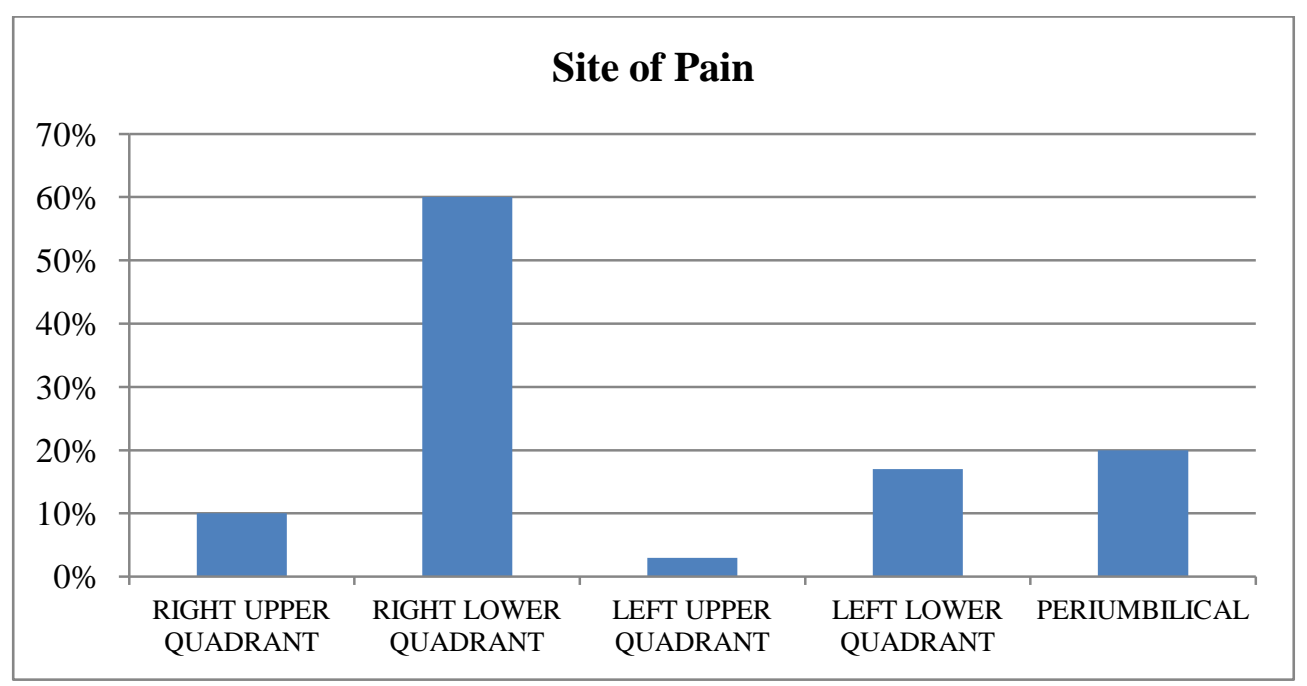

Most of them presented with the right lower quadrant pain which constitutes about $60 \%$, particularly in the right iliac fossa.

\section{Intra operative findings}

\begin{tabular}{|l|c|}
\hline Findings & Percentage \\
\hline Thickened appendix & $16(33 \%)$ \\
\hline Adhesions & $12(23 \%)$ \\
\hline Enlarged mesenteric nodes & $9(17 \%)$ \\
\hline Koch's abdomen & $6(13 \%)$ \\
\hline Neoplasia & $5(10 \%)$ \\
\hline Hernia & $3(7 \%)$ \\
\hline No abnormality & $5(10 \%)$ \\
\hline
\end{tabular}

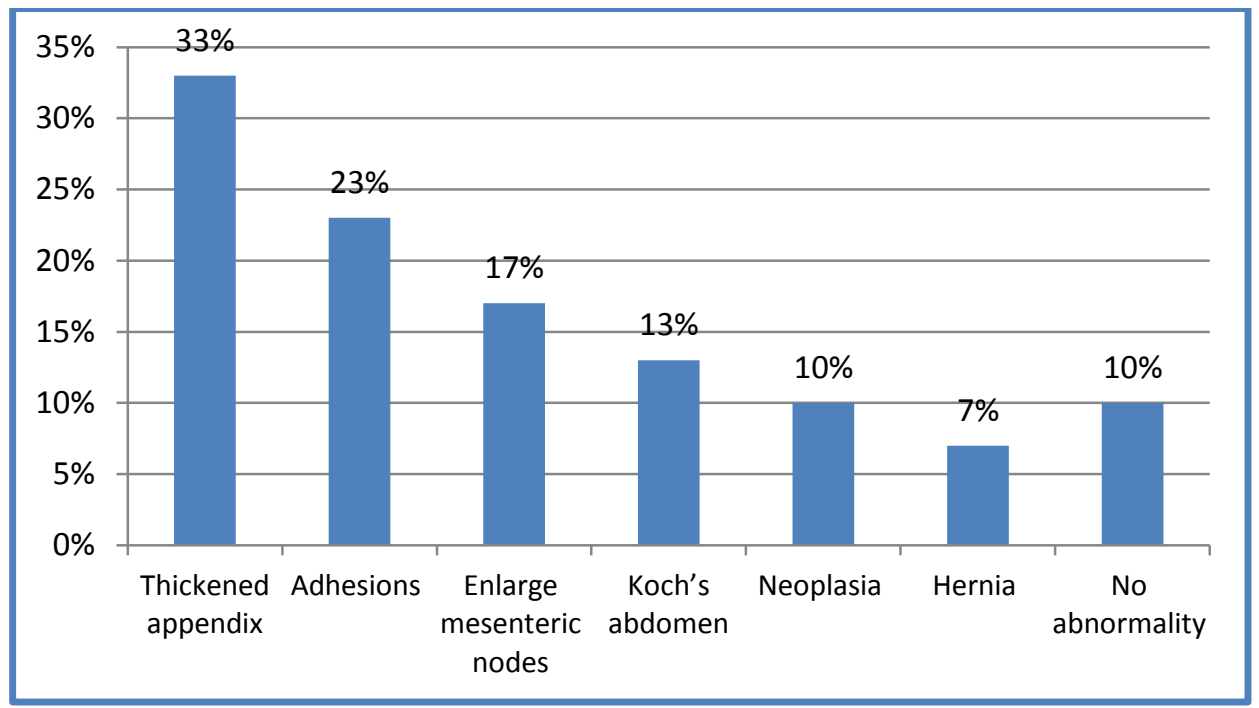


We found that appendicular pathology is the leading cause for abdominal pain for three months or more of unrevealed etiology and it is about $33 \%$, followed by adhesion is about $23 \%$.

Laparoscopic appendicectomy was performed in cases with appendicular pathology like inflamed, thickened appendix and localized adhesion with caceum and abdominal wall. All the histopathological reports of appendix specimen sent, revealed chronic inflammation.

These cases recovered post operatively without any complication and free of pain in 1 month follow up.

Adhesions were found in $23 \%(n=12)$, out of that 6 patients had H/O previous surgery. Two patients underwent open cholecystectomy and other 4 had previous history of LSCS. Omentum was adherent to the anterior abdominal wall in the scar region.

5 patients with previous $\mathrm{H} / \mathrm{O}$ surgery, had undergone laparoscopic adhesiolysis, and two of them were converted into open technique because of the extensive adhesion which could not be managed laparoscopically.

In other 5 patients without previous $\mathrm{H} / \mathrm{O}$ surgery, adhesion of the caecum and appendix to the anterior abdominal wall was found during laparoscopy and adhesiolysis was performed successfully.

Koch's abdomen was diagnosed in $13 \%(n=6)$. Intra operative findings were multiple tubercles over the peritoneum, bowel and omentum. In one case we found that flimsy adhesion between the bowel loops and anterior abdominal wall. In all other four cases minimal ascitic fluid was present. Omental and peritoneal biopsy was taken, ascitic fluid was also sent for biochemical analysis. The results confirmed the tuberculous abdomen. They were started on anti tuberculous drug post operatively.

Malignancy was diagnosed in $(n=5) 10 \%$ of patients. Two of them had metastastic colonic cancer and in one patient, histopathological diagnosis of mesothelioma was made and administered palliative chemotherapy.

$7 \%(n=3)$ of the patients had ventral hernia and underwent hernioplasty. One had small defect in the paraumbilical region with omentum adherent to it; another had omental adhesion in the previous LSCS scar, in whom after reducing the content there was a small defect in one corner of the scar region. Mesh repair was done in both the cases.

History of previous abdominal surgery was found in 4 patients out of which 3 had omental adhesion and one presented with small incisional hernia.

Mean operating time for diagnostic laparoscopy alone is 30 minutes but if combined with therapeutic procedures it was $73 \pm 30$ minutes.

\section{Management}

\begin{tabular}{|l|c|}
\hline Lap interventions & $26(52 \%)$ \\
\hline Biopsy & $24(47 \%)$ \\
\hline Conversion into open & $4(7 \%)$ \\
\hline No interventions & $18(37 \%)$ \\
\hline
\end{tabular}

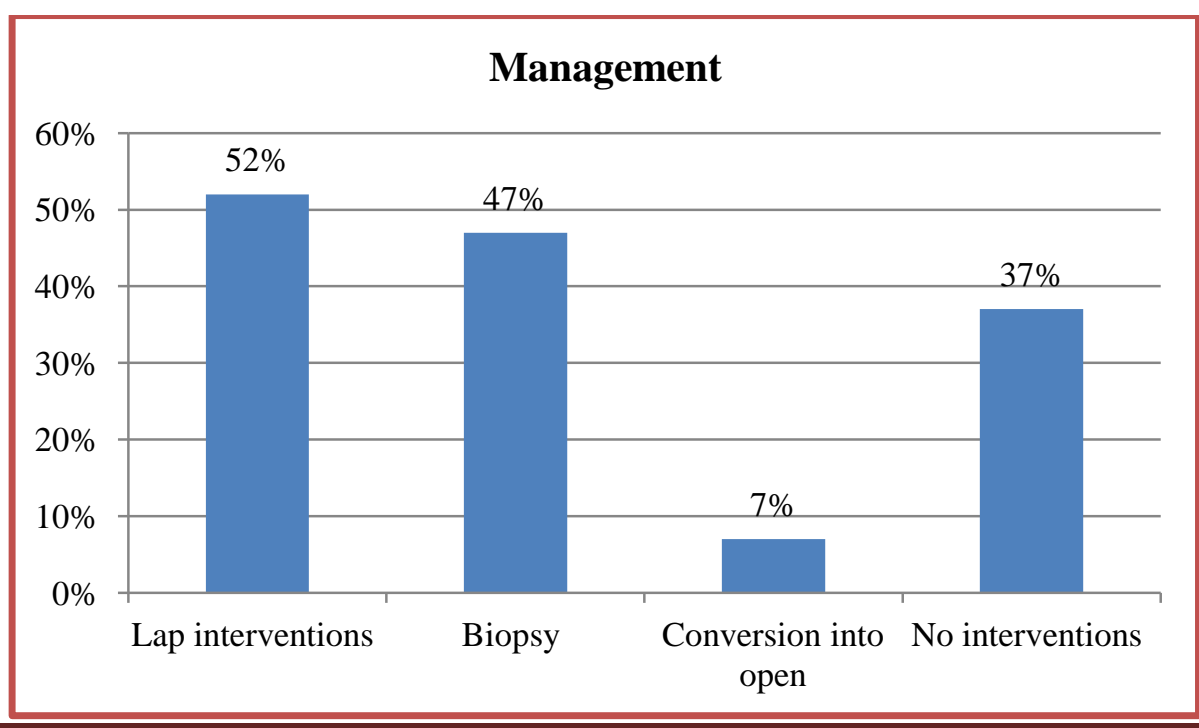


Therapeutic procedure was done in $52 \%(n=26)$ of the patients which includes appendicectomy $55 \%$, adhesiolysis $33 \%$, hernioplasty $11 \%$.

$17 \%(\mathrm{n}=8)$ of the patients had enlarged mesenteric nodes in the terminal ileum which was taken up for biopsy and reports showed features of non specific adenitis.
No abnormality is noted in $7 \%(n=4)$ of the patient suggestive of negative laparoscopy present in our study.

\section{Laparoscopic Intervention}

\begin{tabular}{|l|c|}
\hline Lap interventions & Percentage \\
\hline Appendicectomy & $16(55 \%)$ \\
\hline Adhesiolysis & $12(33 \%)$ \\
\hline Hernia repair & $3(11 \%)$ \\
\hline
\end{tabular}

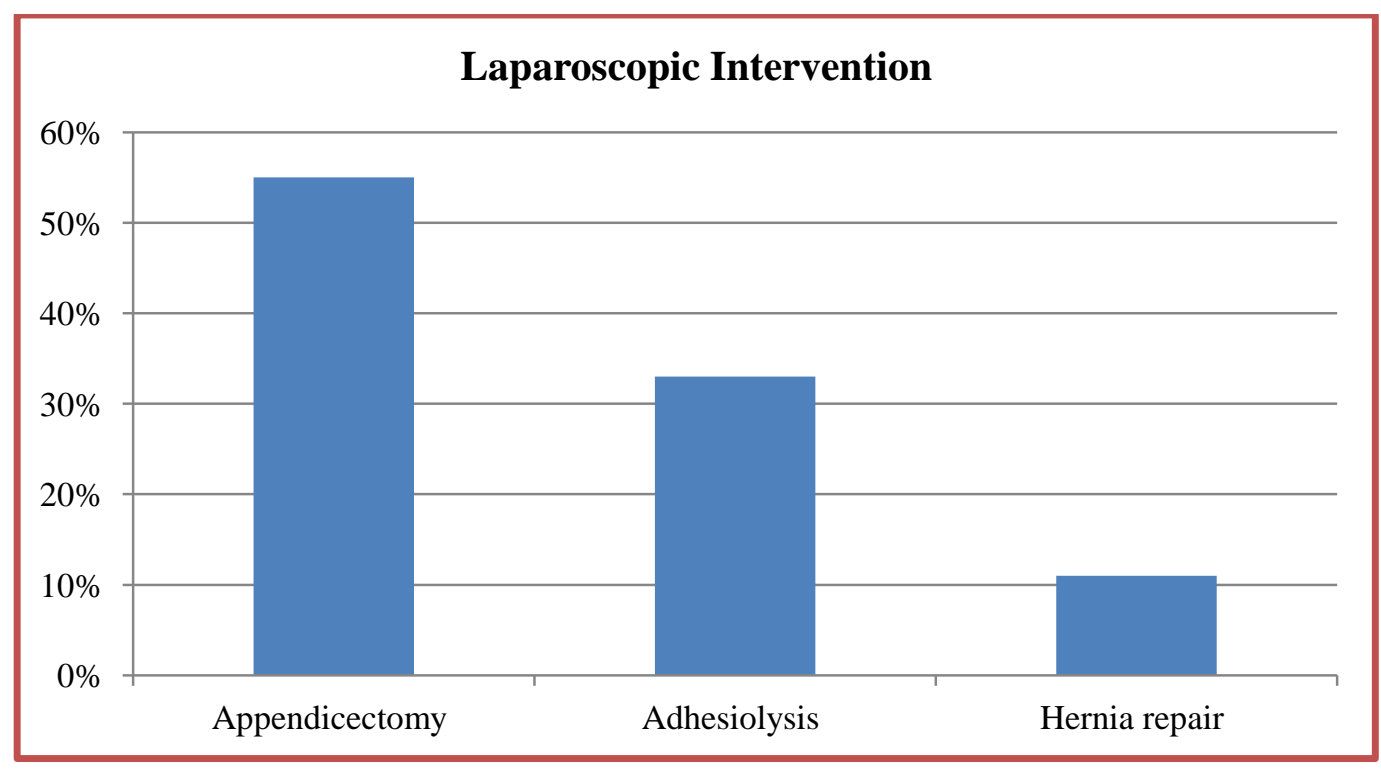

\section{Post op Complications}

\begin{tabular}{|l|l|}
\hline Post op complication & Percentage \\
\hline None & $47(93 \%)$ \\
\hline Infection & $3(7 \%)$ \\
\hline
\end{tabular}

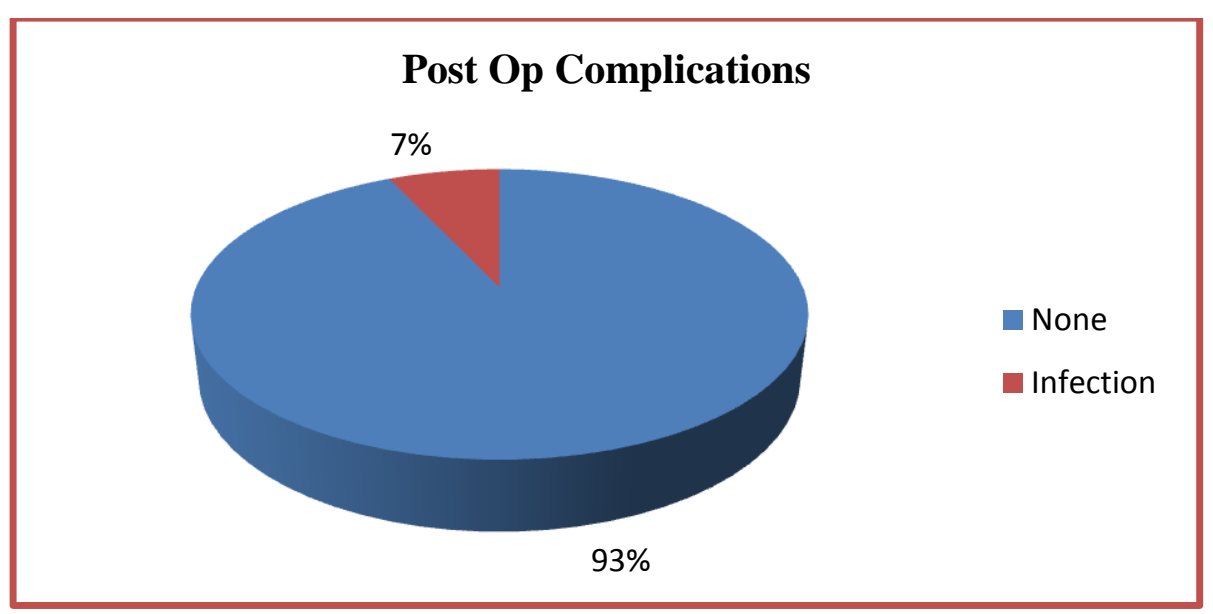

$7 \%(\mathrm{n}=3)$ of cases had wound infection in the post operative period which was minimal and it was managed by appropriate antibiotics and dressing. No other major complication occurred in the intraoperative or post operative period.

Mean Postoperative hospital stay was 2.5 days

\section{Pre op Pain Grading}

\begin{tabular}{|l|c|}
\hline Grading & Percentage \\
\hline Mild & $3(6 \%)$ \\
\hline Moderate & $35(70 \%)$ \\
\hline Severe & $12(23 \%)$ \\
\hline Very severe & $0(0 \%)$ \\
\hline
\end{tabular}




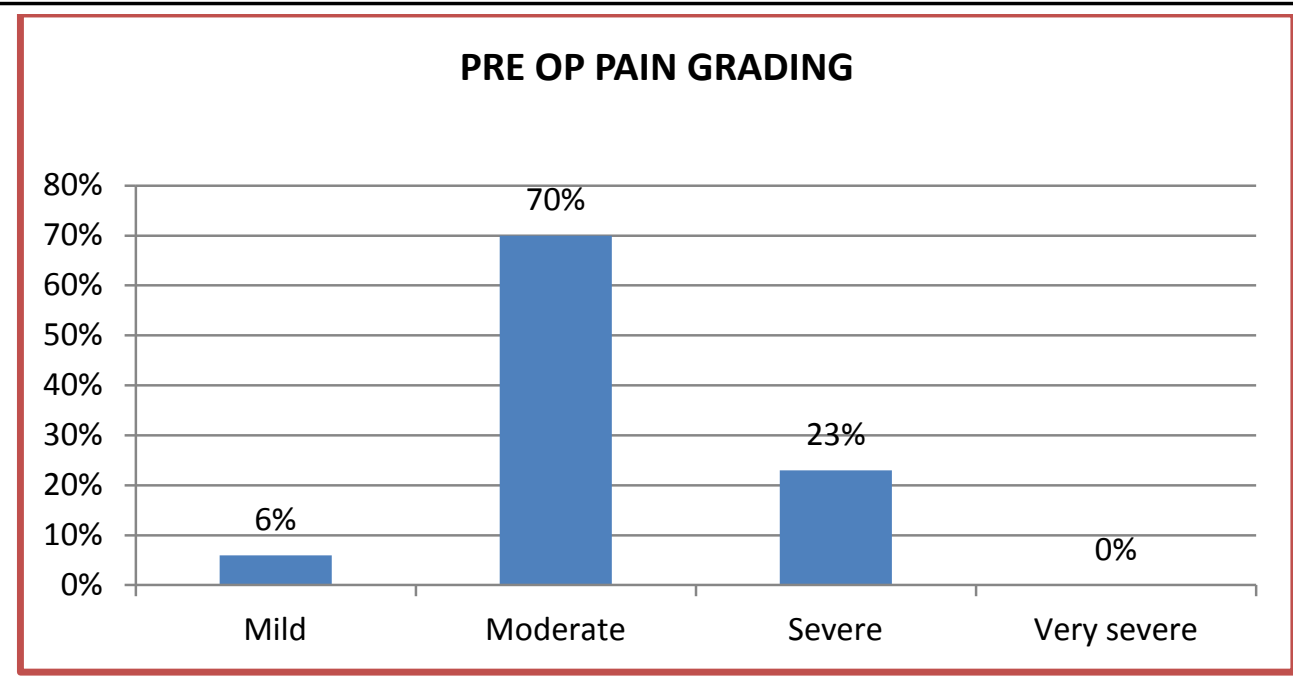

Most of the cases had moderate pain which accounts for $70 \%(n=35)$

\section{Post op Pain Relief}

\begin{tabular}{|l|c|c|}
\hline Duration & Positive out come & Negative out come \\
\hline After 1 month & $80 \%$ & $20 \%$ \\
\hline After 3 month & $90 \%$ & $10 \%$ \\
\hline
\end{tabular}

All cases were observed in the immediate post operative period for pain perception and amount of analgesics needed for treatment. All of them were followed up in $1^{\text {st }}$ month and 3 rd month. Verbal Rating Scale for pain perception was analysed.

At the end of $1^{\text {st }}$ month, $80 \%$ patients got complete pain relief and at $3^{\text {rd }}$ month $90 \%$ got complete pain relief. In remaining $10 \%$ of cases, there were no changes in pain grading, it may be due to course of the disease and the cases, whose laparoscopic findings were normal also were symptom free in the follow up. It may be due to placebo effect.

\section{Discussion}

Chronic abdominal pain is defined as continuous or intermittent pain in the abdomen more than 3 months duration. Diagnosis and treatment of these patients is usually difficult and frustrating.

It is one of the most common surgical symptom and most challenging problem faced by the surgeons and physicians ${ }^{21}$.

We evaluated 50 consecutive patients with chronic abdominal pain with no obvious cause and uncertain diagnosis was evaluated laparoscopically.
No pathological lesion was found in $7 \%$ of the patients. In a similar laparoscopic study by Marana and his coworker ${ }^{22}$ Gowri and Krolikowski $^{23}$, no pathological lesion was found in $20 \%$ of the patients but in our study it was $7 \%$. Common site for chronic abdominal pain is right lower quadrant $(60 \%)$ followed by periumbilical region $(20 \%)$.

Common intra operative findings were abnormal appendix (3\%) followed by adhesions (23\%) which requires appendicectomy and adhesiolysis.

Di Lorenzo and colleagues ${ }^{24}$ reported frequency of abdominal adhesions in chronic abdominal pain were found in $18.6 \%$ but it was $23 \%$ in our study. It was found that location of pain in the site of adhesions was found in $90 \%$ of cases, although there was no correlation between extent of adhesion and severity of pain ${ }^{25}$. The pain in the adhesion is due to restrict mobility and distension of the organ particularly bowel. ${ }^{26}$

$7 \%$ of patients required conversion into open techniques this is because of the extensive bowel adhesions. Positive outcome is $80 \%$ in the follow up of 1 month and $90 \%$ of the patients got complete pain relief in the follow up of 3 months. This figure coincides with Gouda and Emad's 26 study which reports, "the diagnostic laparoscopy yields $80 \%$ positive outcome in evaluation of chronic abdominal pain in the follow up period of 2 months." 


\section{Conclusion}

Diagnostic laparoscopy is a minimally invasive surgical procedure that allows complete visualisation of the intra-abdominal organs for making accurate diagnosis. Laparoscopy is useful in evaluating patients with chronic abdominal pain, in whom various imaging modalities are not conclusive to obtain a definite diagnosis.Due to advent of laparoscopy negative non therapeutic laparotomies are reduced. Diagnostic Laparoscopy is helpful in making a definite diagnosis and provides proper management of patients. The therapeutic value of diagnostic laparoscopyis also accepted, well-appreciated, and it cannot be underestimated.. It has also significantly reduced the number of investigations that these patients are subjected to, days of hospital stay, which leads to substantial reduction in the cost of the treatment Diagnostic laparoscopy is a safe, relatively costeffective and efficient method for finding out the etiology of chronic abdominal pain and to provide specific interventions.

\section{References}

1. Camilleri M. Management of patients with chronic abdominal pain inclinical practice. Neurogastroenterol Motil 2006;18:499506.

2. Townsend CO, Sletten CD, Bruce BK, Rome JD, Luedtke CA, Hodgson JE. Physical and emotional functioning of adult patients with chronic abdominal pain: Comparison with patients with chronic back pain. J Pain 2005;6:75-83.

3. McGarrity TJ, Peters DJ, Thompson C, McGarrity SJ. Outcome ofpatients with chronic abdominal pain referred to chronic pain clinic. Am JGastroenterol 2000;95:1812-6.

4. Paajanen $\mathrm{H}$, Julkunen $\mathrm{K}$, Waris $\mathrm{H}$. Laparoscopy in chronic abdominal pain: A prospective nonrandomized long-term follow-up study. J ClinGastroenterol 2005;39:110-4.
5. Ferrell BR. The impact of pain on quality of life. A decade of research. NursClin North Am 1995;30:609-24.

6. Magni G, Rossi MR, Rigatti-Luchini S, Merskey H. Chronic abdominalpain and depression. Epidemiologic fi ndings in the United States. Hispanic health and nutrition examination survey. Pain 1992;49:77-85.

7. Peters AA, Van den Tillaart SA. The diffi cult patient in gastroenterology: Chronic pelvic pain, adhesions, and sub occlusive episodes.Best Pract Res Clin Gastroenterol 2007;21:445-63.

8. van Goor H. Consequences and complications of peritoneal adhesions. Colorectal Dis 2007;9:25-34.

9. Arya PK, Gaur KJ. Laparoscopy: A tool in the diagnosis of lower abdominal pain. Indian J Surg 2004;66:216-20.

10. Lindsetmo RO, Stulberg J. Chronic abdominal wall pain - A diagnostic challenge for the surgeon. Am J Surg 2009;198:129-34.

11. Costanza CD, Longstreth GF, Liu AL. Chronic abdominal wall pain: Clinical features, health care costs, and long-term outcome. Clin Gastroenterol Hepatol 2004;2:395-9.

12. Galili O, Shaoul R, Mogilner J. Treatment of chronic recurrent abdominal pain: Laparoscopy or hypnosis? J Laparoendosc Adv Surg Tech A2009;19:93-6.

13. Salky BA, Edye MB. The role of laparoscopy in the diagnosis and treatment of abdominal pain syndromes. Surg Endosc 1998;12:911-4.

14. Klingensmith ME, Soybel DI, Brooks DC. Laparoscopy for chronic abdominal pain. Surg Endosc 1996;10:1085-7.

15. Mueller MD, Tschudi J, Herrmann U, Klaiber C. An evaluation of laparoscopic adhesiolysis in patients with chronic abdominal pain. Surg Endosc 1995;9:8024. 
16. Onders RP, Mittendorf EA. Utility of laparoscopy in chronic abdominal pain. Surgery 2003;134:549-52.

17. Ikard RW. There is no current indication for laparoscopic adhesiolysis to treat abdominal pain. South Med J 1992;85:939-40.

18. Swank DJ, Swank-Bordewijk SC, Hop WC, van Erp WF, Janssen IM, Bonjer HJ, et al. Laparoscopic adhesiolysis in patients with chronic abdominal pain: A blinded randomised controlled multi-centre trial. Lancet2003;361:1247-51.

19. Yousaf M, Hosuy MA. Small bowel obstruction after laparoscopic inguinalhernia repair. J Coll Physicians Surg Pak 2001;11:721-2.

20. Graham A, Henley C, Mobley J. Laparoscopic evaluation of acuteabdominal pain. J Laparoendosc Surg 1991;1:165-8.

21. Marana, R.; Paielli, FV.; Muzii, L. and Mancusol, $\mathrm{J}$ : the role of laparoscopy in evaluation of chronic abdominal pain. Minerva Gyneco. 1993; Jun 45(6): 281-6;

22. V \& Krolikowski Gowri, A.: Chronic pelvic pain. Laparoscopic and 70

23. Di Lorenzo, N.; Coscarella, G.; Lirosi, F.; Faraci, L. and Rossi,p.: Impact of laparoscopic surgery in the treatment of chroic abdominal pain sysdrome. Chir tal. 2002;54(34): 367-78

24. Mahawar, K.K.: Laparoscopic adhesiolysis in patients with chronic abdominal pain. Lancet(England). 2003; 361 (9376)

25. Swank, D.J.; Van Erpo, W.F.; Repelaer, O.J.; Hop, W.C. and Bonjer, H.J.: A prospective analysis of predictive factors on the results of laparoscopic adhesiolysis in patients with chronic abdominal pain. Surg Laparosc Endosc.2003; 13(2): 88-94.
26. Gouda M El-laddan,Emad N Hokkam The efficacy of laparoscopy in the diagnosis and management of chronic abdominal pain. J Min access Surg 2010; 6:95-9. 